\title{
Pelvic organ prolapse symptoms in relation to POPQ, ordinal stages and ultrasound prolapse assessment
}

\author{
Kirsten B. Kluivers • Jan C. M. Hendriks • Clara Shek • \\ Hans Peter Dietz
}

Received: 4 January 2008 / Accepted: 1 April 2008/ Published online: 9 May 2008

(C) The Author(s) 2008

\begin{abstract}
Adequate staging of pelvic organ prolapse is important in clinical practice and research. The ability of the POPQ, ordinal stages and ultrasound prolapse assessment were evaluated for their ability to discriminate between women with and without prolapse symptoms. The leading edge of the predominant compartment in the three assessment systems was used for the calculation of receiver operating characteristics curves. Two hundred and sixty five (265) consecutive women were evaluated. The area under the receiver operating characteristics curve for the three staging systems ranged from 0.715 to 0.783 . POPQ staging and ordinal staging performed equally well in the prediction of prolapse symptoms $(p=0.780)$, and both performed better as compared with ultrasound prolapse assessment ( $p=0.048$ and $p=0.015$, respectively). Prolapse staging can equally be performed by the POPQ and ordinal stages systems as far as the discrimination between women with and without prolapse symptoms is concerned. The ultrasound prolapse assessment does not perform better as compared with these two systems.
\end{abstract}

\footnotetext{
K. B. Kluivers $(\triangle)$

791, Department of Obstetrics and Gynaecology,

Radboud University Nijmegen Medical Centre,

Postbus 9101, 6500 HB, Nijmegen, The Netherlands

e-mail: K.Kluivers@obgyn.umcn.nl
}

J. C. M. Hendriks

Department of Epidemiology and Biostatistics,

Radboud University Nijmegen Medical Centre,

Nijmegen, The Netherlands

C. Shek $\cdot$ H. P. Dietz

Nepean Clinical School, University of Sydney,

Penrith, Australia
Keywords Ordinal stages · Pelvic organ prolapse · Symptoms $\cdot$ POPQ $\cdot$ Staging $\cdot$ Translabial ultrasound

\section{Introduction}

Adequate staging of pelvic organ prolapse is of paramount importance in clinical practice and research. Reporting on prolapse stages in a standardized manner enables the evaluation of anatomical outcome after surgical treatment and the comparison of populations. The Pelvic Organ Prolapse Quantification system (POPQ), the ordinal stages as derived from the POPQ and ultrasound prolapse assessment are among the systems used for this purpose. The POPQ and ordinal stages have been introduced in 1996 as a more valid staging system as compared with the Baden-and-Walker system, dating from 1972 [1]. In the POPQ system, prolapse is assessed in centimetres relative to the hymen, and these assessments can be translated into five ordinal stages (Stage 0-4). Translabial 2D-ultrasound prolapse assessment has been first described in 2001 [2]. The prolapse is assessed in millimetres relative to a fixed bony reference point (the infero-posterior margin of the symphysis pubis), which, in theory, provides more detailed measurements in millimetres descent. In addition, information is obtained regarding the nature of the prolapse, e.g. allowing distinction between rectocele, enterocele, perineal hypermobility and rectal intussusception [3]. With the help of $3 \mathrm{D} / 4 \mathrm{D}$ ultrasound imaging it is also possible to obtain information on biometry and morphological abnormalities of the levator muscle and hiatus [3].

Logistic regression and receiver operating characteristic curves (ROC-curves) can be used to assess the usefulness of a diagnostic test for a certain condition. In the present 
study, the three prolapse staging systems were regarded as diagnostic tests for prolapse symptoms. The most valid question to identify women with more severe stages of prolapse are: 'do you feel or see a lump in the vagina?' [4-9], which were used to identify women with and without prolapse symptoms.

Until now, data on the value of ultrasound prolapse quantification as compared to the POPQ and ordinal staging systems, in relation to pelvic organ prolapse symptoms, are lacking. Equally, the POPQ system, which is relatively complex and for this reason has been adopted only slowly, has not been examined for its performance in predicting prolapse symptoms as compared with the ordinal stages. Since POPQ and ultrasound staging assess prolapse in centimetres and millimeters, respectively, we hypothesized that their ability to discriminate between women with and without symptoms of pelvic organ prolapse would be superior to the ordinal staging.

\section{Materials and methods}

Patients presenting to a single urogynaecologist (HPD) between July 2005 and December 2006, with pelvic organ prolapse symptoms or lower urinary tract dysfunction were included in this prospective observational study. Symptomatic prolapse was diagnosed when patients confirmed the oral question that they had the sensation or visualisation of a vaginal lump.

All women underwent prolapse staging using the POPQ system, ordinal stages and translabial ultrasound. The examinations took place in the supine position. The leading edge of the most descended compartment in each staging system was used. There was no standard sequence of staging systems. The examiner was not blinded to the results from other staging systems, since no significant differences have previously been found in this respect [2].

For POPQ staging, the point $\mathrm{Ba}$ (leading edge on anterior vaginal wall), $\mathrm{C}$ (leading edge of cervix or vaginal vault), and $\mathrm{Bp}$ (leading edge on posterior vaginal wall) were determined in centimetres above or below the hymen on maximum Valsalva manoeuvre [1]. In the ordinal stages the prolapse was quantified as anterior vaginal wall, uterine or vaginal vault descent, and posterior vaginal wall Stage $0-4$. The definition for these stages was as described by Bump et al. [1].

For the ultrasound prolapse assessment, translabial ultrasonography was carried out in the midsagittal plane using an 8-4 MHz transabdominal transducer (Voluson 730 expert, GE Kretz Ultrasound, Zipf, Austria) [10]. On maximum Valsalva, the maximum descent of the leading edge of the bladder, the cervix or vaginal vault, the cul the sac and the rectum was determined in millimetres relative to the infero-posterior margin of the symphysis pubis [2].

Logistic regression was used to determine the performance of each diagnostic test in detecting symptomatic prolapse, and the ROC-curves are presented. The dependent variable was the presence of symptoms of prolapse while the independent variable was the staging system. The differences amongst the three areas under the ROC-curves (AUC) were tested for statistical significance as described by Delong et al. [11]. The cut-off point on each ROC-curve, using the principle of equal costs of misclassification of women with and without prolapse symptoms, was assessed, i.e. maximum sum of sensitivity and specificity. Data were analyzed using SPSS 12.0.1 (SPSS, Inc., Chicago, IL, USA) and SAS 10.0 (SAS institute, Inc., Chicago, IL, USA). The $p$ value for statistical significance was set at $<0.05$. This was a sub analysis of a parent study approved by the Human Research Ethics Committee of the Sydney West Area Health Service under reference number 05-029.

\section{Results}

Two hundred and eighty nine (289) consecutive women were evaluated during the study period. Two hundred and sixty five (265) women, of whom the data on all three staging systems were available, were included in the study. One hundred and forty eight women (56\%) were asymptomatic and 117 (44\%) were symptomatic for prolapse. The mean age was 54.2 years (standard deviation 14.0), and mean parity was 2.5 (standard deviation 1.3). Prior hysterectomy had been performed in $29 \%$ of women, and $11 \%$ of women had had prior incontinence surgery. Ordinal stage 0 or 1 was present in $49 \%$, stage 2 in $31 \%$ and stage 3 or 4 in $20 \%$ of women. On ultrasound assessment, the leading edge of the prolapse was the bladder in $44 \%$, an enterocele in $7 \%$, the uterus or vaginal vault in $4 \%$ and the rectum in $46 \%$ of cases.

The AUC, indicating the probability of symptoms of prolapse with increasing stages, was $0.778(95 \% \mathrm{CI} 0.721$; $0.835)$ for the POPQ, $0.783(95 \% \mathrm{CI} 0.729 ; 0.838)$ for ordinal stages and $0.715(95 \% \mathrm{CI} 0.653 ; 0.777)$ for ultrasound quantification. The cut-off point, with equal costs of misclassification, was at the hymen $(0 \mathrm{~cm})$ in the POPQ, stage 2 in the ordinal stages and $14 \mathrm{~mm}$ below the reference line through the symphysis pubis (i.e. $-14 \mathrm{~mm}$ ) in ultrasound prolapse assessment. The ROC-curves and cutoff points are presented in Fig. 1. All three staging systems were able to distinguish between symptomatic and asymptomatic women $(p<0.01)$. The performance of the POPQ and ordinal stages was equal $(p=0.780)$, and both were superior to the ultrasound prolapse assessment in the 


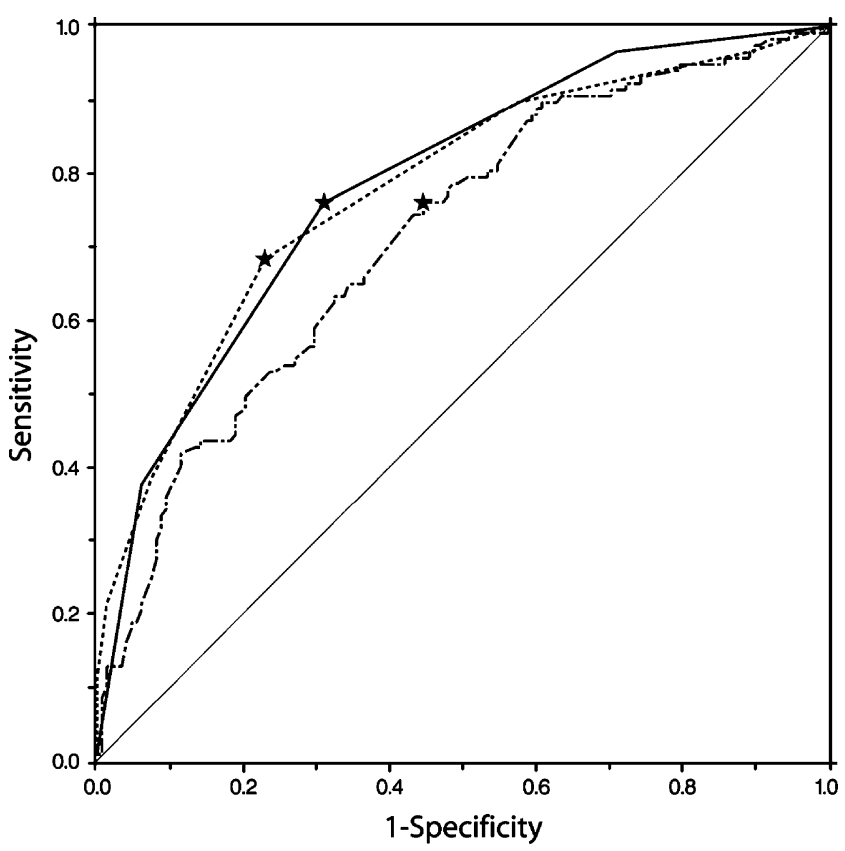

Fig. 1 Receiver operating characteristics curves representing the ability of the POPQ (dotted line), the ordinal stages (solid line) and ultrasound prolapse assessment (broken line) to predict prolapse symptoms. For reference the $x=y$ line is shown. The stars indicate the cut-off point in each staging system, using the principle of equal costs of misclassification. This refers to the hymen $(0 \mathrm{~cm})$ in the POPQ, stage 2 in the ordinal stages and $14 \mathrm{~mm}$ below the reference line through the symphysis pubis in ultrasound prolapse assessment

prediction of symptoms of prolapse ( $p=0.048$ and $p=0.015$, respectively).

\section{Discussion}

In this study, the probability of prolapse symptoms with increasing degree of prolapse as assessed by three staging systems was evaluated. No differences amongst POPQ and ordinal stages were found, whereas the ultrasound prolapse assessment performed less well as compared with the other two. This finding was not consistent with our hypothesis.

The POPQ system was introduced as a more valid tool for the assessment of pelvic organ prolapse [1]. The main rationale for expecting improved validity was the measurement of descent in centimetres instead of the four or five stages in the Baden-and-Walker or similar systems. However, to our knowledge, the POPQ has never been tested for its performance as a test in diagnosing symptomatic prolapse as compared to the correlated ordinal stages. The results of our study argue against the POPQ conferring any improvement in diagnostic accuracy.

On ultrasound prolapse assessment the descent of each compartment can be measured in millimetres. However, this again does not seem to lead to a consequent improvement in prediction of prolapse symptoms. This may be due to the difference in reference line, which are the symphysis pubis in ultrasound staging and the hymen in POPQ. The hymenal remnants are thought to be a relative limit for asymptomatic prolapse $[1 ; 8]$, whereas the symphysis pubis is not. This is particularly true for the posterior compartment, where we did not differentiate between true rectoceles and other causes of posterior compartment descent. Significant descent of the rectal ampulla may be detected on ultrasound without any concomitant vaginal bulging. Although such descent may be of relevance for anorectal function, it is unlikely to lead to the sensation of a vaginal lump. Separate analysis of the three compartments, with a focus on isolated single compartment prolapse, will require much larger numbers, but is likely to help with further investigating the relationship between organ descent and symptoms of prolapse.

Although ultrasound was not able to increase the prediction of prolapse symptoms as compared to the other two staging systems in this study, it has significant other advantages, such as the detection of true rectocele (i.e. a defect of the rectovaginal septum), of enterocele and rectal intussusception [12]. Furthermore, access to the axial plane can detect levator trauma [13], which seems to be a (hitherto unrecognised) major cause of pelvic organ prolapse in parous women [14]. To a degree, the same would be expected of other forms of imaging such as dynamic magnetic resonance imaging [15].

A limitation of the study is that no validated method of prolapse symptom assessment was used. The question on the sensation or visualisation of a vaginal lump or bulge was the only question, however, which was found positively correlated with pelvic organ prolapse before [6]. In future studies, a validated questionnaire on prolapse symptoms, for example, could be used to overcome this problem. Another limitation of the study is that the examiner was not blinded to the result of the prolapse symptom assessment and the results on the different staging systems. In a previous study, however, no significant differences have been found in this respect for the groups with and without blinding for the staging systems [2].

In conclusion, prolapse staging can equally be performed by the POPQ system or ordinal stages as far as the discrimination between women with and without prolapse symptoms is concerned. This draws into question the routine use of the POPQ system and may support the viewpoint of those clinicians who have been reluctant to adopt the POPQ, instead relying on the simplified ICS staging system. Furthermore, ultrasound quantification of prolapse is not superior to these two systems when considered as a test for symptomatic prolapse. Although the POPQ and ultrasound have the theoretical advantage of 
measuring descent in centimetres and millimeters, respectively, and may be more discriminatory as regards treatmentrelated changes over time, and although ultrasound may better distinguish between different forms of prolapse than clinical examination, this advantage is not reflected in a higher discriminatory power as regards symptoms of prolapse.

\section{Financial interest or support None.}

Conflicts of interest Hans Peter Dietz has acted as a consultant for AMS and CCS, has received speaker's honoraria from General Electric, AMS and Astellas and has had support through equipment loans from General Electric and Bruel \& Kjaer.

Open Access This article is distributed under the terms of the Creative Commons Attribution Noncommercial License which permits any noncommercial use, distribution, and reproduction in any medium, provided the original author(s) and source are credited.

\section{References}

1. Bump RC, Mattiasson A, Bø K, Brubaker LP, DeLancey JO, Klarskov P et al (1996) The standardization of terminology of female pelvic organ prolapse and pelvic floor dysfunction. Am J Obstet Gynecol 175:10-17

2. Dietz HP, Broome J, Haylen BT (2001) Ultrasound quantification of uterovaginal prolapse. Ultrasound Obstet Gynecol 18:511-514

3. Dietz HP (2006) Why pelvic floor surgeons should use ultrasound imaging. Ultrasound Obstet Gynecol 28:629-634
4. Digesu GA, Chaliha C, Salvatore S, Hutchings A, Khullar V (2005) The relationship of vaginal prolapse severity to symptoms and quality of life. BJOG 112:971-976

5. Bradley CS, Nygaard IE (2005) Vaginal wall descensus and pelvic floor symptoms in older women. Obstet Gynecol 106:759-766

6. Barber MD, Neubauer NL, Klein-Olarte V (2006) Can we screen for pelvic organ prolapse without a physical examination in epidemiologic studies. Am J Obstet Gynecol 195:942-948

7. Tan JS, Lukacz ES, Menefee SA, Powell CR, Nager CW, San Diego Pelvic Floor Consortium (2005) Predictive value of prolapse symptoms: a large database study. Int Urogynecol J Pelvic Floor Dysfunct 16:203-209

8. Swift S, Woodman P, O, Boyle A, Kahn M, Valley M, Bland D et al (2005) Pelvic Organ Support Study (POSST): the distribution, clinical definition, and epidemiologic condition of pelvic organ support defects. Am J Obstet Gynecol 192:795-806

9. Ellerkmann RM, Cundiff GW, Melick CF, Nihira MA, Leffler K, Bent AE (2001) Correlation of symptoms with location and severity of pelvic organ prolapse. Am J Obstet Gynecol 185:332-337

10. Dietz HP (2004) Ultrasound imaging of the pelvic floor. Part II: three-dimensional or volume imaging. Ultrasound Obstet Gynecol 23:615-625

11. DeLong ER, DeLong DM, Clarke-Pearson DL (1988) Comparing the areas under two or more correlated receiver operating characteristic curves: A nonparametric approach. Biometrics 44:837-845

12. Dietz HP, Steensma AB (2005) Posterior compartment prolapse on two-dimensional and three-dimensional pelvic floor ultrasound: the distinction between true rectocele, perineal hypermobility and enterocele. Ultrasound Obstet Gynecol 26:73-77

13. Dietz H (2007) Quantification of major morphological abnormalities of the levator ani. Ultrasound Obstet Gynecol 29:329-334

14. Dietz HP, Simpson J (2008) Levator trauma is associated with pelvic organ prolapse. Br J Obstet Gynaecol (in press)

15. DeLancey JO, Morgan DM, Fenner DE, Kearney R, Guire K, Miller JM et al (2007) Comparison of levator ani muscle defects and function in women with and without pelvic organ prolapse. Obstet Gynecol 109:295-302 